\title{
The use of the colon as a substitute for the oesophagus
}

\author{
P. J. CHRYSOSPATHIS AND B. GOLEMATIS \\ From the Second Surgical Department, University of Athens, Greece
}

EDITORIAL SYNOPSIS Thirty-one cases of oesophagoplasty are reported using different parts of the colon. The use of the left colon in an isoperistaltic direction is recommended, and the operative technique and post-operative results are described.

The use of the colon as a replacement for the oesophagus seems to offer advantages over the other methods of oesophagoplasty and is nowadays used by many surgeons. Vulliet and Kelling (Vulliet, 1911) were the first to utilize the large bowel for this purpose, and thereafter a number of similar publications have followed, most of them describing successful results. The segment of the colon to be preferred was the cause of many discussions. Some (Mahoney and Sherman, 1954; Neville and Clowes, 1958; Sherman, Mahoney, Dale, and Stabins, 1955; Scanlon and Staley, 1958;Chrysospathis, 1957) claim favourable results with the right colon but transverse colon has also been successfully used in many cases (Montenegro and Cutait, 1958). In the recent literature a few cases of oesophagoplasty with the left half of the colon (Orsoni and Lemaire, 1951) placed isoperistaltically (Beck and Baronofsky, 1960; Montenegro and Cutait, 1958) are reported.

The purpose of this article is to present our experience with this operation, i.e., the use of the left colon in an isoperistaltic direction, as a comparison with the results we have obtained using different parts of the colon. No extensive review of the literature is intended in this paper.

In 1953 we did the first oesophagoplasty with the large gut in a young girl aged 17 years for an extensive fibrous stricture of the oesophagus caused by the accidental ingestion of caustic soda. We made use of the right colon and a portion of the terminal ileum $(15 \mathrm{~cm}$.) placed isoperistaltically. The result was very good and this encouraged us to try it on other similar cases. Since then we have performed this substitution operation in $\mathbf{3 1}$ instances of benign and malignant lesions of the oesophagus, using different parts of the colon.

In five of our cases of oesophagoplasty right colon, with 10 to $20 \mathrm{~cm}$. of terminal ileum, was placed isoperistaltically. In using this part of the colon we occasionally encountered anatomical variations of the right colic vessels, which did not allow us to isolate a sufficient viable length of this segment of the gut as did Toupet (1951). We, therefore, investigated the possibility of using the left half of the colon (transverse plus descending) pedicled on the right colic or the middle colic artery. Dissatisfaction with the post-operative regurgitation, due to the antiperistaltic placing of the transverse colon, led us to isoperistaltic oesophagoplasty with this segment of the colon, an operation which is now successfully performed in our Department.

\section{OPERATIVE TECHNIQUE}

The operation is performed in one or two stages. The abdomen is opened through an upper midline incision which is extended to a little below the umbilicus. We make sure whether or not the stomach is affected by the lesion of the oesophagus. The distribution of the vessels is then carefully examined with the help of transmitted illumination.

As a preliminary step we apply non-crushing clamps to the colic vessels to be ligated for 10 minutes in order to test the adequacy of the marginal blood supply of the transposed loop. We regard the watching of the pulsations of the little marginal arteries as a simple and reliable test which has, in our opinion, proved to be of great assistance.

The placing of the isolated colonic loop inside or outside the chest cavity depends on the nature of the disease which is affecting the oesophagus. The practice of this clinic is a retrosternal position in young patients with caustic atresia and an antethoracic (subcutaneous) position in patients with malignant lesions when a radical excision of the growth or a palliative bypass operation is performed.

If the right colon is selected for transposition the right colic vessels are usually preserved and the ileocolic ligated. The large omentum is dissected from the trans- 


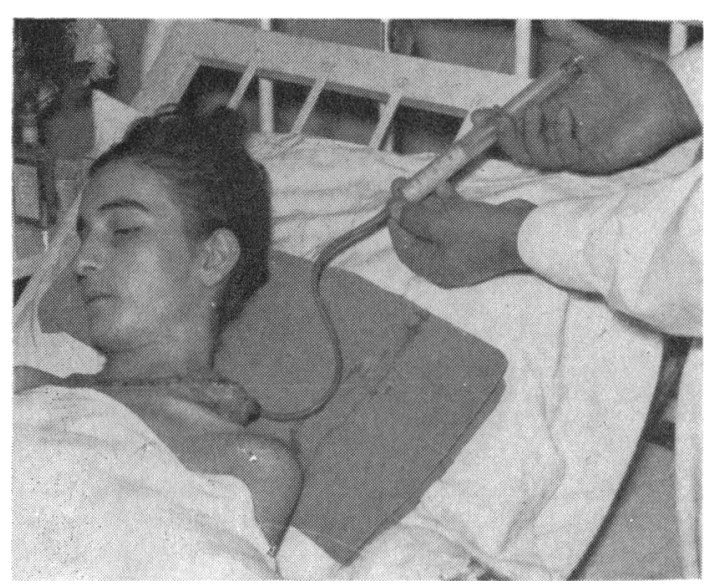

FIG. 1. Cervical colostomy.

verse colon and the hepatic flexure mobilized. The transverse colon divided close to the hepatic flexure is used as the distal end, and the ileum divided 10 to $20 \mathrm{~cm}$. from the ileocaecal valve as the proximal end. Having finished the mobilization of the transplant, a retrosternal or a prethoracic tunnel is created and through this the grafted segment of the colon is gently drawn up to the neck. The distal stump is then anastomosed end-to-side with the anterior wall of the stomach near the antrum. Two rows of sutures are used, the first mucosal with catgut and the second serosal with fine $(00)$ silk. If a radical oesophagectomy was carried out a pyloroplasty was added. If the operation is performed in one stage, an end-to-side oesophago-ileostomy is made with two layers of fine silk.

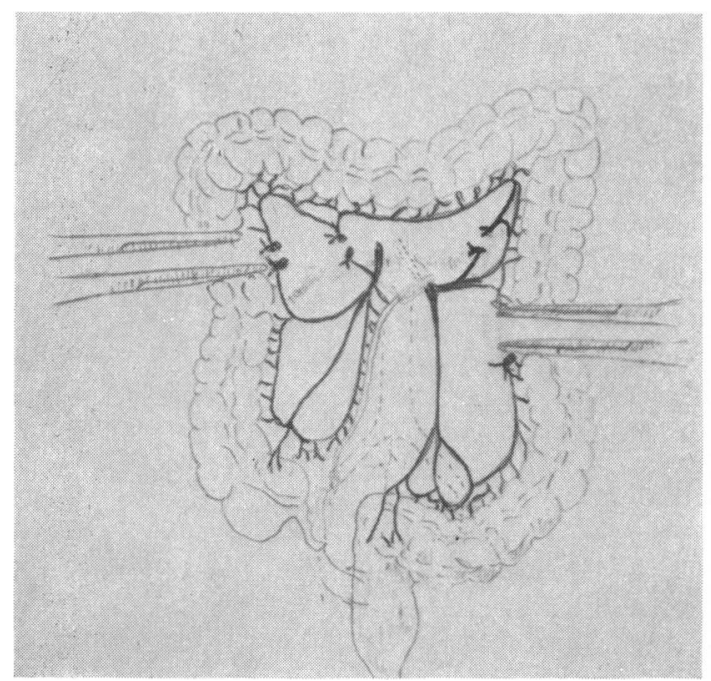

In the two-stage operation the open end of the ileum is then fixed to the left side of the neck (Fig. 1) and a feeding catheter is ingested through the ileostomy (Chrysospathis, Golematis, and Campanis, 1961). The recurrent laryngeal nerves must not be damaged while dividing the cervical oesophagus. A small tube is left in the distal end of the oesophagus which is partially sutured and solutions of antibiotics are for some days introduced through this tube to prevent possible mediastinitis. Intestinal continuity is re-established with an end-to-end ileo-transverse anastomosis.

When the left colon is used both the hepatic and the splenic flexures are mobilized. The right colic vessels are in most instances preserved. The middle colic vessels can sometimes be used for the purpose. In both cases the transposed colonic loop is placed in an antiperistaltic direction (Figs. 2 and 3). If the intestinal loop is pedicled on the left colic artery it can be easily placed isoperistaltically, after having measured the distance from the abdomen to the neck. The restoration of the continuity of the colon is made with an end-to-end colo-colonic anastomosis with interrupted sutures of fine silk in two layers. This intervention, except for the difference in the mobilization of the intestinal loop, follows the same stages as those described for the right colon.

\section{RESULTS}

From 1953 to 1960 inclusive 31 patients with extensive cicatricial stenosis and cancer of the oesophagus were subjected to oesophagoplasty using different parts of the colon.

In our series of cases six post-operative deaths occurred. In one case the operation was done for caustic atresia in a young girl and was due to peritonitis. One death was caused by haemorrhage

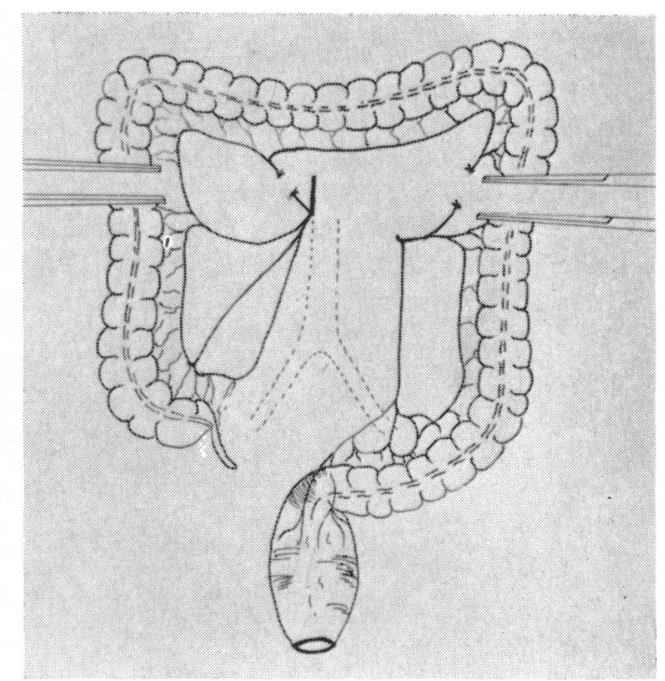

FIG. 2

FIGS. 2-3. Operative diagrams of the transposed colonic loop when placed in isoperistaltic and antiperistaltic directions. 


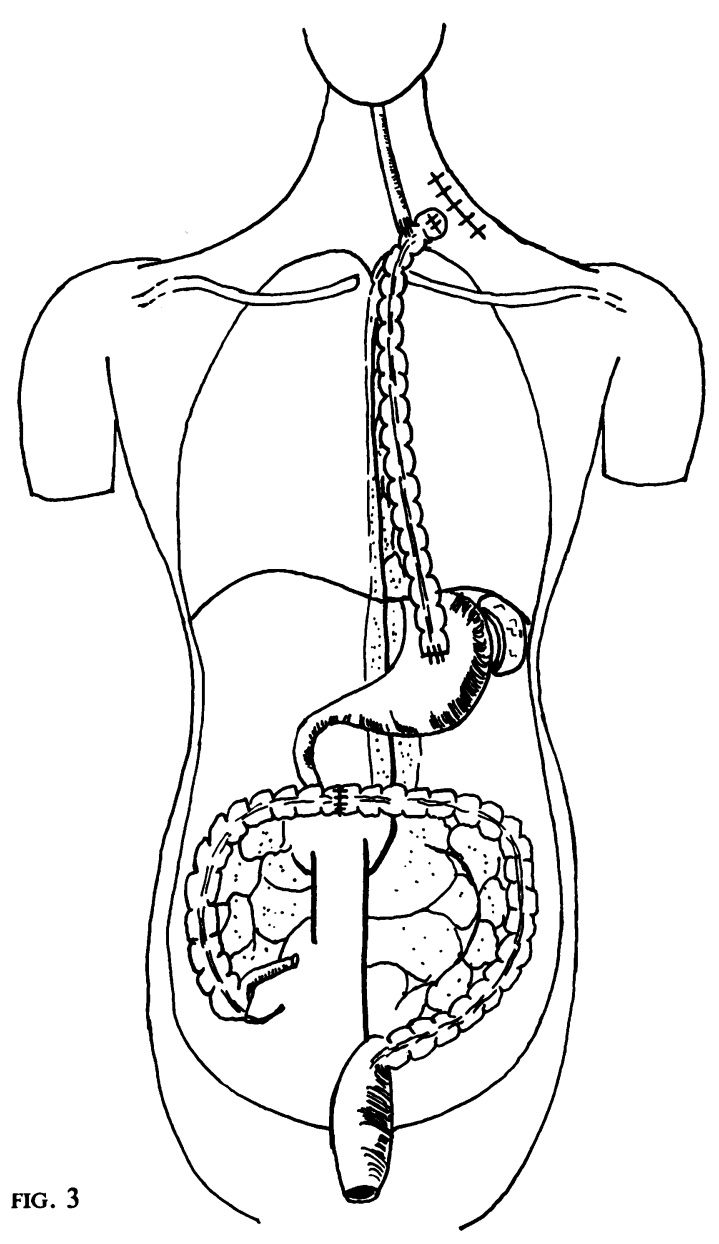

of the unremoved oesophageal tumour four days after the palliative bypass oesophagoplasty, and another by a pulmonary embolism.

The remaining three deaths followed radical oesophagectomy and were due, one to mediastinitis and the other two to a hepatorenal syndrome and cardiac failure.

Of the 25 patients who successfully underwent oesophagoplasty the survival rate was as follows.

TABLE I

RESULTS IN 31 CASES

\begin{tabular}{|c|c|c|}
\hline Disease & Number of Cases & Deaths \\
\hline $\begin{array}{l}\text { Cicatricial strictures of the oesophagus } \\
\text { Inoperable (palliative oesophagoplasty) } \\
\text { Cancer of the oesophagus } \\
\text { Operable (radical oesophagectomy) }\end{array}$ & $\begin{array}{ll}17 & \\
& 8 \\
14 & \\
& 6\end{array}$ & $\begin{array}{ll}1 & \\
5 & 2 \\
& 3\end{array}$ \\
\hline Total & 31 & 6 \\
\hline
\end{tabular}

TABLE II

SEGMENT OF COLON TRANSPLANTED IN 31 OESOPHAGOPLASTIES

\begin{tabular}{lc} 
Segment of the Colon & Cases \\
\hline R. colon (isoperistaltically) & 12 \\
Transverse colon (antiperistaltically) & 6 \\
L. colon (isoperistaltically) & 13 \\
Total & 31
\end{tabular}

Sixteen patients with cicatricial stenosis are back in full employment. Of the three patients who had a radical oesophagectomy, one is still alive one and a half years after the operation, another died after eight months, and the last one is doing well six months after the operation. Of the six patients who underwent a palliative bypass oesophagoplasty, two died six months after the operation, one is still active three years later, and another is doing a certain amount of work two years after the operation. The last two are living four and five months after the operation and their general condition has been greatly improved.

All our patients subjected to oesophago-coloplasty for extensive scarring of the oesophagus are getting on very well and living a normal life.

\section{COMPLICATIONS}

Most of the patients with cicatricial stenosis due to accidental or deliberate ingestion of chemical substances were young. Two of these patients developed a psychosis five to 10 days after the operation and refused to take their meals. The cervical colostomy with a feeding catheter proved to be of great assistance in these cases and permitted the administration of a continuous drip of milk and of various kinds of soups. Both patients were transferred to a psychiatric clinic and after receiving electro-shock therapy made excellent recoveries.

On one occasion while making the retrosternal tunnel the pleura was opened and a pneumothorax resulted which lasted for two months.

In another case an inflammatory granuloma of the oesophagocolic anastomosis developed two months after the operation, causing dysphagia. This patient was readmitted and a fresh anastomosis was made and thereafter he made an excellent recovery.

In patients with antiperistaltic placing of the colon regurgitation appears early in the post-operative period but gradually subsides on antispasmodic treatment.

Delay in emptying of the colonic oesophagus may occasionally occur, usually with the right colon oesophagoplasty, but this subsides without any serious effect. 


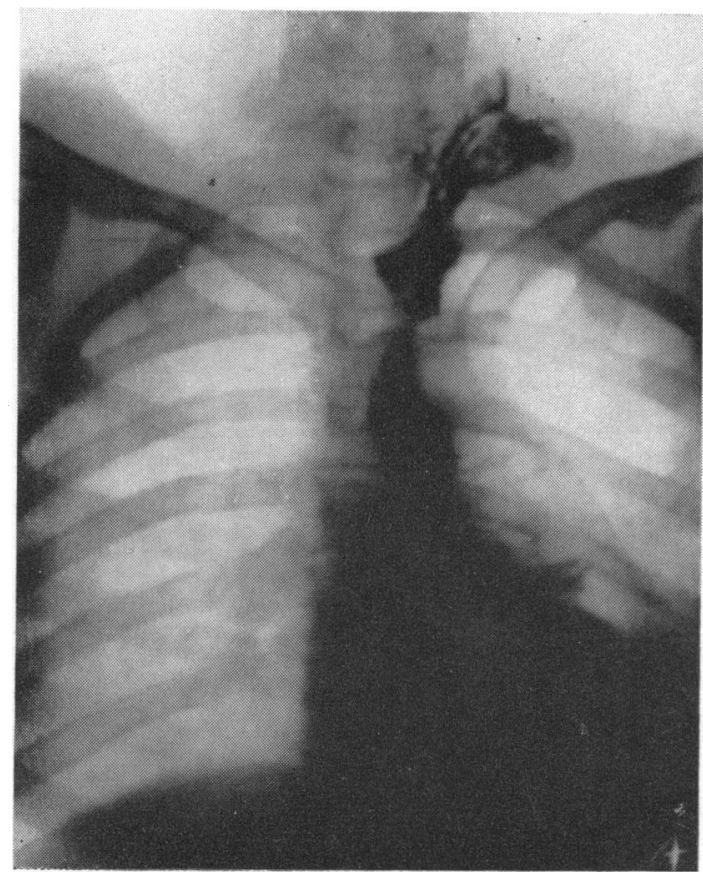

FIG. 4a.

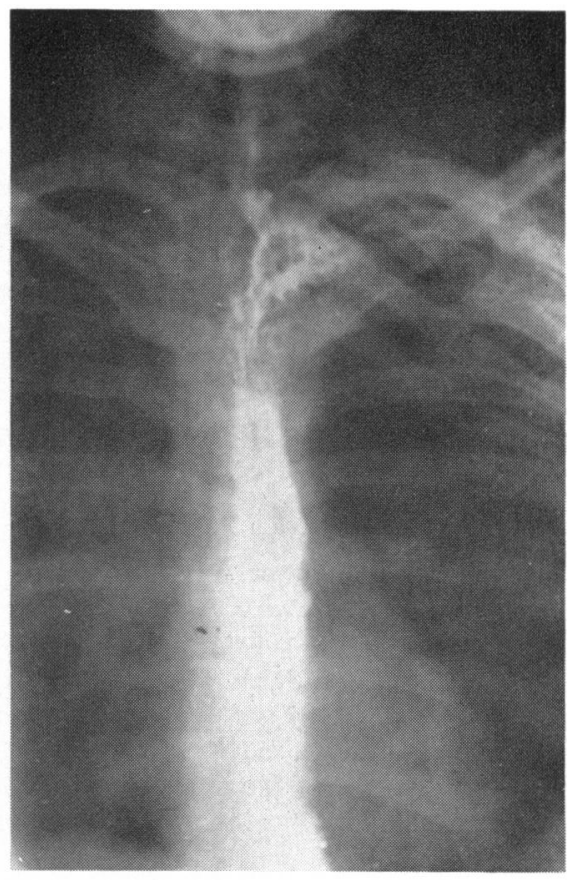

FIG. 4b.

FIG. 4. Radiographs showing operative result (a) two years and (b) four years after operation.

\section{COMMENT}

Oesophagoplasty with colon transplantation has, in our experience, many advantages.

The operation is carried out in one stage for goodrisk patients with benign strictures of the oesophagus and in cases of unresectable cancer of this organ when a palliative bypass oesophagoplasty is performed. A two-stage procedure is used for the treatment of cancer of the oesophagus if a radical oesophagectomy is carried out. The first stage consists of the prethoracic placing of the isolated portion of the colon, combined with a temporary gastrostomy. Deep $x$-ray therapy is then given to the oesophagus and the mediastinum. If the patient responds well to this treatment the oesophagus is resected at a second operation. We prefer the staged procedure for radical surgery of this organ as it allows the feeding up of those undernourished patients and offers them a better chance for a radical curative operation after three to six months.

The palliative bypass operation, apart from the psychological effect in enabling the patient to swallow, improves his general condition and on the average adds something to his comfort and happiness (Chrysospathis, Procos, and Golematis, 1960).

Our experience with radical oesophagectomy for cancer is still small, and does not permit us to estimate its real curative value.

The cervical colostomy or ileostomy is closed two to three weeks after the operation with interrupted sutures of fine silk when the normal function of the oesophago-colic anastomosis has been assured. Leaking from this anastomosis was not observed when using this procedure.

Orsoni and Toupet (1950) have proposed an anastomosis of the colonic graft with the jejunum instead of with the stomach. Montenegro and Cutait (1958) join the proximal colonic stump with the gastric fundus. Both report good results.

The actual distance to be traversed from the abdomen to the neck is always taken with a flexible measure, and during the operation we have never failed to obtain an adequate length of colon to cover the distance.

A barium enema was given to all our patients for a radiological control of the function of the colon. Associated diseases of the colon, such as diverti- 
culitis, colitis, multiple polyposis, if known preoperatively or found at operation, contraindicate its use in oesophagoplasty.

It is interesting to note that in all our cases of oesophagoplasty we have not, so far, seen any peptic lesion develop in the transplanted colon.

We tend now to perform oesophagoplasty by mobilizing the left colon (part of the transverse and part of the descending colon) which is easily placed isoperistaltically and is provided with a good blood supply by the left colic artery. In this method one has to be careful to leave intact the vascular bifurcation at the splenic flexure (Fig. 2). For the time being we are happy using the left colon placed in an isoperistaltic position for the following reasons:-

In all our cases the barium meal through the new oesophagus was found to be satisfactory, even in the first post-operative period. Regurgitation is avoided. The small diameter of the lumen of this part of the colon is also an essential advantage. A long length with a good blood supply is easily isolated.

Finally, one should not forget intestinal asepsis with the usual drugs (sulphapathalidine, streptomycin, and neomycin) and the mechanical preparation of the colon.

We wish to express our warmest thanks to Mr. Norman C. Tanner and to Mr. A. Chirnside for their care and help in publishing this article.

\section{REFERENCES}

Beck, A. R., and Baronofsky, I. D. (1960). A study of the left colon as a replacement for the resected esophagus. Surgery, 48, 499-509.

Chrysospathis, P. I. (1957). Extensive cicatricial stenosis of the esophagus: Treatment by retrosternal transposition of the colon: Report of five cases. J. int. Coll. Surg., 27, 656-663.

- Golematis, B., and Campanis, N. (1961). One- or two-stage cervical esophagocolostomy or ileostomy for replacement of the esophagus. Surgery, 49, 429-432.

_- Procos, G., and Golematis, B. (1960). Esophagocoloplasty as a palliative surgical procedure for inoperable carcinoma of the esophagus. J. int. Coll. Surg., 34, 292-297.

Mahoney, E. B., and Sherman, C. D. (1954). Total esophagoplasty using intrathoracic right colon. Surgery, 35, 937-946.

Montenegro, E. B., and Cutait, D. E. (1958). Construction of a new esophagus by means of the transverse colon and its application for caustic atresia, carcinoma, and varices of the esophagus. Report of 26 cases. Ibid., 44, 785-794.

Neville, W. E, and Clowes, G. H. A., Jr. (1958). Reconstruction of the esophagus with segments of the colon. J. thorac. Surg., $35,2-22$.

Orsoni, P., and Lemaire, M. (1951). Technique des oesophagoplasties par le côlon transverse et descendant. J. Chir. (Paris), 67, 491-505.

__ and Toupet, A. (1950). Utilisation du côlon descendant et de la partie gauche du cỏlon transverse pour l'oesophagoplastie pré-thoracique. Presse méd., 58, 804.

Scanlon, E. F., and Staley, C. J. (1958). The use of the ascending and right half of the transverse colon in esophagoplasty. Surg. Gynec. Obstet., 107, 99-103.

Sherman, C. D., Jr., Mahoney, E. B., Dale, W. A., and Stabins, S. J. (1955). Intrathoracic transplantation of the right colon for esophageal reconstruction. Cancer, 8, 1198-1205.

Toupet, A. (1951). Quelques considérations sur la vascularisation des côlons et leurs abaissements dans la chirurgie du côlon gauche et du rectum. Rev. Chir. (Paris), 89 (Année 70), 70-92.

Vulliet, H. (1911). De l'oesophagoplastie et de ses diverses modifications. Sem. méd. (Paris), 31, 529-530. 